\title{
Uniform-related infection control practices of dental students
}

\author{
Yazan Aljohani' \\ Mohammed Almutadares' \\ Khalid Alfaifi' \\ Mona El Madhoun' \\ Maysoon H Albahiti ${ }^{2}$ \\ Nadia Al-Hazmi ${ }^{3}$ \\ 'Internship Program, Faculty of \\ dentistry, King Abdulaziz University, \\ ${ }^{2}$ Department of Endodontics, King \\ Abdulaziz University, ${ }^{3}$ Department \\ of Oral Biology, King Abdulaziz \\ University, Faculty of Dentistry, \\ Jeddah, Saudi Arabia
}

This article was published in the following Dove Press journal:

Infection and Drug Resistance

24 April 2017

Number of times this article has been viewed

Background: Uniform-related infection control practices are sometimes overlooked and underemphasized. In Saudi Arabia, personal protective equipment must meet global standards for infection control, but the country's Islamic legislature also needs to be taken into account.

Aim: To assess uniform-related infection control practices of a group of dental students in a dental school in Saudi Arabia and compare the results with existing literature related to crosscontamination through uniforms in the dental field.

Method: A questionnaire was formulated and distributed to dental students at King Abdulaziz University Faculty of Dentistry in Jeddah, Saudi Arabia, which queried the students about their uniform-related infection control practices and their methods and frequency of laundering and sanitizing their uniforms, footwear, and name tags.

Results: There is a significant difference between genders with regard to daily uniform habits. The frequency of uniform washing was below the standard and almost $30 \%$ of students were not aware of how their uniforms are washed. Added to this, there is no consensus on a unified uniform for male and female students.

Conclusion: Information on preventing cross-contamination through wearing uniforms must be supplied, reinforced, and emphasized while taking into consideration the cultural needs of the Saudi society.

Keywords: cross-contamination, infection control, dental students, uniforms

\section{Background}

In dentistry, cross-contamination is the transmission of infectious microorganisms between patients and the dental staff in a clinical setting. ${ }^{1,2}$ The main modes of transmission are direct, including aerosol transmission (occurs by contact with oral fluids and blood), indirect transmission (occurs by contact with contaminated equipment and surfaces), and inhalation of airborne pathogens. ${ }^{3}$ Ultrasonic scalers, hand pieces and air polishers, commonly used in the dental clinic, produce aerosols that contain blood, saliva, calculus, restorative materials, and pathogenic microorganisms, rendering the dental clinic a hazardous environment. For this reason, cross-contamination is a frequently discussed issue in the dental field. ${ }^{4-6}$ In fact, such aerosols may cause the transmission of tuberculosis, common cold, influenza, herpetic viruses' infection, hepatitis B and C, and $\mathrm{HIV}^{4}$ Variability of infectious aerosols produced during coughing by patients with pulmonary tuberculosis. ${ }^{7}$

Aerosol and splatter created during dental procedures travel upwards in a vertical, expanding, funnel-shaped, circular pattern contaminating the operator's chest, shoulders, face, and lower arms. ${ }^{8-10}$ Pathogens can remain on clothing for up to several
Correspondence: Nadia Al-Hazmi Department of Oral Biology, King Abdulaziz University, Faculty of Dentistry, P.O. Box 80498, Jeddah 21589, Saudi Arabia

Tel +966506378349

Email nalhazmi@kau.edu.sa 
days; for instance, HBV-contaminated blood, transmitted through clothing, can survive and remain infectious for 7 days, even after the blood has dried..$^{9-11}$ Scrubs and lab coats are identified as attire worn by health professionals in clinical environments and are described as the "uniform" of health professionals. In addition, personal protective equipment (PPE) in the form of disposable gowns, disposable gloves, disposable masks, and protective eyewear, is mandatory when performing invasive dental procedures., ${ }^{3,12}$ There are many concerns that the attire may be a vehicle for the transmission of pathogens since HBV can survive in the clinical setting; however, a systematic review found no evidence of microorganisms being transferred from uniforms to patients in a clinical setting. ${ }^{13,14}$

In our dental school, any personnel working in any clinical area are required to dress in "clinical attire" in the form of scrubs without a lab coat or a lab coat covering normal clothing if scrubs are not worn. When actively working on patients, all personnel are mandated to wear a disposable gown over their clinical attire (scrub or lab coat) and are required to remove such disposable gown at the end of the clinical session or if it becomes visibly contaminated. While mandatory PPE is provided by the university free of charge to all practicing clinicians, uniforms (such as scrubs and lab coats) are purchased by the students (and other personnel) individually. Therefore, the aim of our work was to assess the uniform-related infection control practices of dental students at King Abdulaziz University in Jeddah, Saudi Arabia, and compare the results with existing literature related to crosscontamination through uniforms in the dental field.

\section{Methods}

A multiple-choice format questionnaire was developed and pretested on a focus group to ensure questions were clear. The following is a sample of the questions:

- Do you wear a gown when treating patients? (a) Yes; (b) No; (c) Sometimes

- Do you wash your uniform separately from other household clothes? (a) Yes; (b) No; (c) I do not know

- When do you take off your clinical uniform? (a) Before leaving the dental school; (b) As soon as I go home without going anywhere else; (c) At home after I have gone out in a public setting

Ethical approval from the Ethical Committee at King Abdulaziz University Faculty of Dentistry (KAUFD) was obtained, and the questionnaire was distributed to all students practicing in clinics (4th, 5th, and 6th year students). Verbal informed consent was obtained from all respondents, and responses were anonymous and voluntary to encourage participation and to avoid biases. Exclusion criteria included incomplete questionnaires. The rationale for this exclusion was that students who did not complete the 12-item questionnaire probably did not answer diligently (this assumption was not based on evidence but was decided by the authors when only 15 questionnaires were returned incomplete, and the remaining 342 questionnaires did not require adjustments for incomplete items). Responses from students in all 3 years were combined using Windows Excel 2010 and SPSS 16.0 to show the statistical trends and were sorted by age group and gender.

For the purpose of this study the "dental uniform" was further divided into scrubs, lab coats, street wear (bottoms only with scrub tops), name tags, and footwear since each student has a preference within the permitted clinical uniform, as allowed by the infection control policies and procedures of the dental school.

\section{Results}

The total number of students attending the clinical years ( 4 th, 5th, and 6th year) were given questionnaires $(n=375)$. Three hundred and fifty-seven questionnaires were returned, giving a response rate of $95.2 \%$. Fifteen of the questionnaires were returned incomplete and were dismissed (4.2\%), giving a final number of 342 questionnaires that were analyzed $(n=342)$. The respondents' ages ranged between 20 and -27 years old with $95 \%$ of the respondents aged $21-24$ years old. Two hundred and thirteen participants were female $(62.28 \%)$ and 129 were male (37.71\%).

The students' responses regarding their daily clinical uniforms are compiled in Figure 1. Most male students wear scrubs only while most female students wear scrubs under lab coats.

Results show that 95 males $(73.6 \%)$ were more relaxed about leaving the clinical setting in their uniform to go to social gatherings such as lunch, as compared to $119(56.1 \%)$ female students and also scored lower on having specific footwear for the clinical setting, washing their uniforms separately, and using bleach as a disinfectant (Table 1).

When asked whether or not they wear a disposable gown while treating patients, 124 (95.9\%) male students and 208 $(97.5 \%)$ female students said "yes". When asked whether they disinfect their name badge/hospital card, 17 (13\%) male students said "yes", and only $16(7.4 \%)$ females said "yes". The students' responses to frequency of scrubs/everyday pants washing showed that only $61(47.2 \%)$ male students and $138(64.7 \%)$ female students wash their uniforms after every use (Tables 2 and 3 ). 


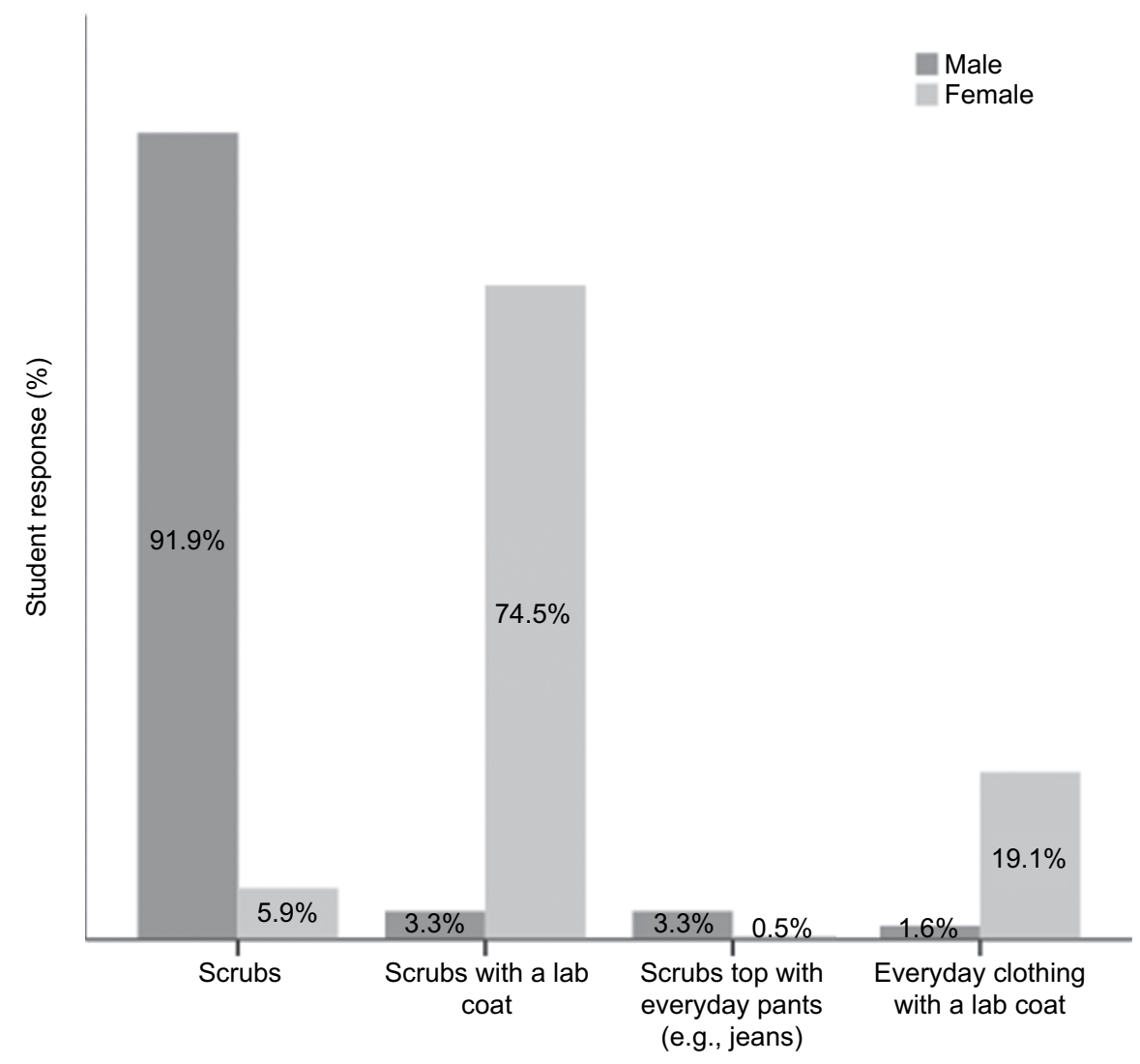

Figure I Type of daily clinical uniform.

Table I Common uniform-related practices carried out by students

\begin{tabular}{lllll}
\hline & Students & Yes (\%) & No (\%) & I do not know (\%) \\
\hline Having footwear specifically for the dental clinic (not worn in & Male & $38 \%$ & 62 & \\
other places) & Female & 50.2 & 49.8 \\
Socializing (e.g., going out for lunch) wearing your clinical & Male & 73.6 & 26.4 & \\
uniform after treating a patient & Female & 56.1 & 43.9 & 18.8 \\
Washing clinical uniform separately from other household & Male & 42.2 & 39.1 & 19.8 \\
clothes & Female & 49.1 & 31.1 & 31.78 \\
Using bleach to disinfect uniform & Male & 30.23 & 37.98 & 37.98 \\
& Female & 40.09 & 27.83 \\
\hline
\end{tabular}

When asked regarding their routine of wearing their clinical uniform (whether from home or once they reached their clinics), students responded mostly "from home" $110(85.4 \%)$ males and 190 (89.2\%) females. The students' responses regarding when they take off their clinical uniforms show that 113 (87.8\%) male students and 193 (90.7\%) female students take their uniforms off after reaching home (Table 2).

The students' responses regarding frequency of washing their lab coats show that only 17 (8.1\%) male students wash their lab coats after each use, compared to 143 (67.2\%) female students (Figures 2 and 3).
Table 2 Use of disposable gowns as part of personal protective equipment

\begin{tabular}{llll}
\hline & & Always (\%) & Not always (\%) \\
\hline Wearing a disposable & Male students & 95.9 & 4.1 \\
gown while treating & Female students & 97.5 & 2.5 \\
patients & & \\
\hline
\end{tabular}

Lastly, students' responses regarding frequency of washing footwear shows that only $3(2.4 \%)$ and $7(3.4 \%)$ males and females respectively, wash them regularly after clinical sessions (Figure 4). Most students wash their footwear less frequently than on a monthly basis. 
Table 3 Student practices in regards to official clinical uniforms

\begin{tabular}{|c|c|c|c|c|c|}
\hline Disinfecting name badge/ & & Yes (\%) & No (\%) & Sometimes (\%) & Do not wear one (\%) \\
\hline \multirow[t]{2}{*}{ hospital card } & Male students & 13 & 34.1 & 11.4 & 41.5 \\
\hline & Female students & 7.4 & 47.1 & 13.2 & 32.4 \\
\hline \multirow[t]{3}{*}{ Wearing clinical uniform } & & \multicolumn{2}{|c|}{ At home (\%) } & \multicolumn{2}{|c|}{ On arrival at school (\%) } \\
\hline & Male students & 85.4 & & 14.6 & \\
\hline & Female students & 89.2 & & 10.8 & \\
\hline \multirow[t]{3}{*}{ Taking off clinical uniform } & & \multicolumn{2}{|c|}{$\begin{array}{l}\text { Before leaving } \\
\text { school (\%) }\end{array}$} & Once at home (\%) & $\begin{array}{l}\text { Later in the day } \\
\text { (socialize while wearing it) (\%) }\end{array}$ \\
\hline & Male students & \multicolumn{2}{|l|}{3.3} & 87.8 & 8.9 \\
\hline & Female students & \multicolumn{2}{|l|}{3.9} & 90.7 & 5.4 \\
\hline
\end{tabular}

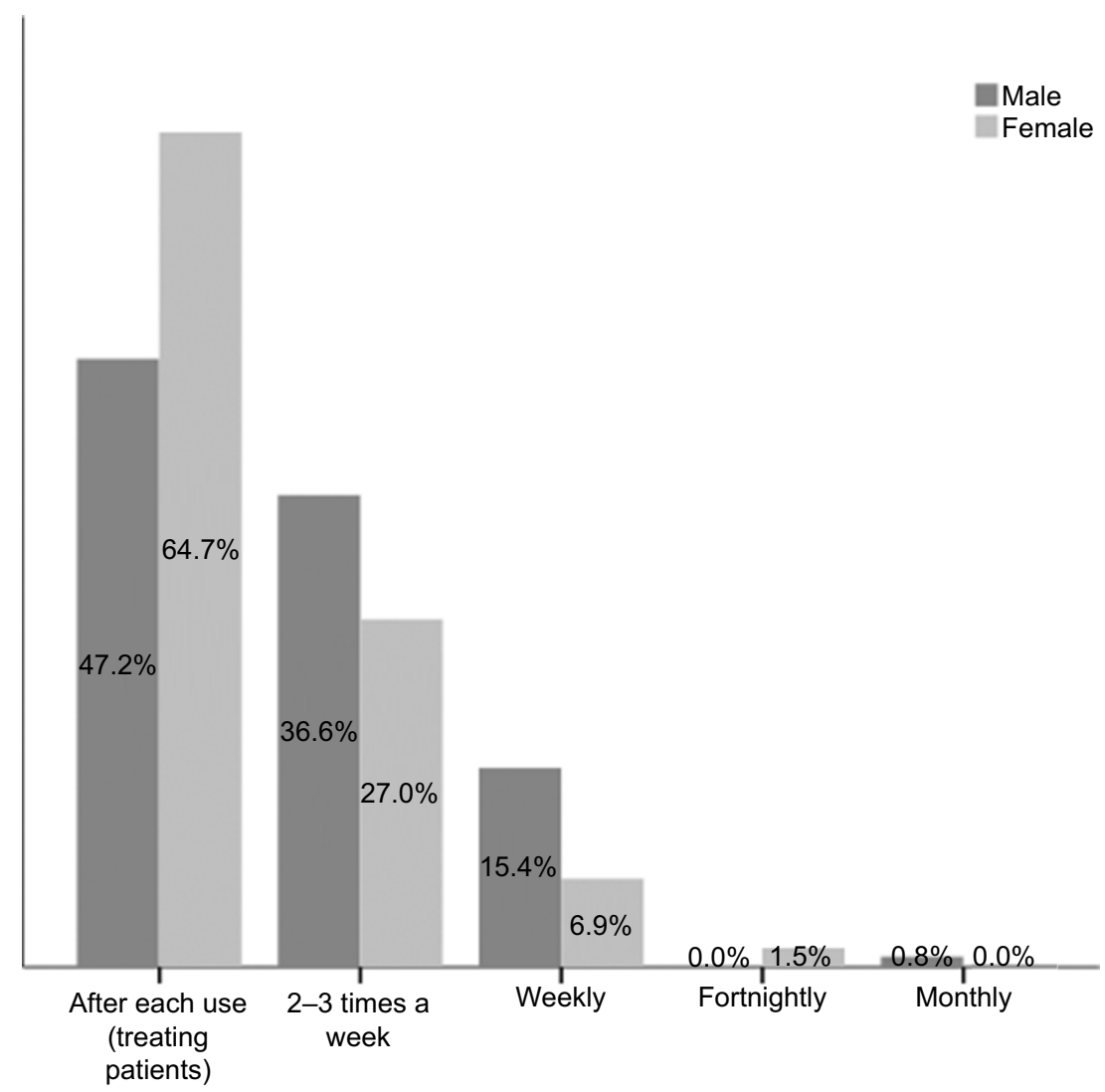

Figure 2 Frequency of washing scrubs/everyday pants.

\section{Discussion}

KAUFD has a written Islamic Ethics and Code of Professional Conduct document where the guidelines regarding what is acceptable and not acceptable as dress code/uniform in the patient care areas are highlighted. Policies on how to clean infected uniforms, as well as policies on PPE use are described in detail in the KAUFD Infection Control Manual. Both documents are available for download on the institute's website (http://dentistry.kau.edu.sa/content.aspx?Site

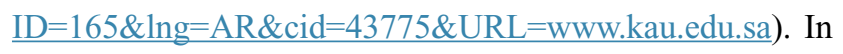

our dental institute, curriculum guidelines are benchmarked against many international organizations and are not limited to a particular region. Examples include the American Dental Association and the United Kingdom National Health Service (NHS). Students are given a lecture on infection control practices at the beginning of every academic year, which instructs them on how to dress appropriately for clinics; how to manage and clean their uniforms; the correct use of PPE, as well as other regulations, and are made aware of the downloadable manual on the website. 


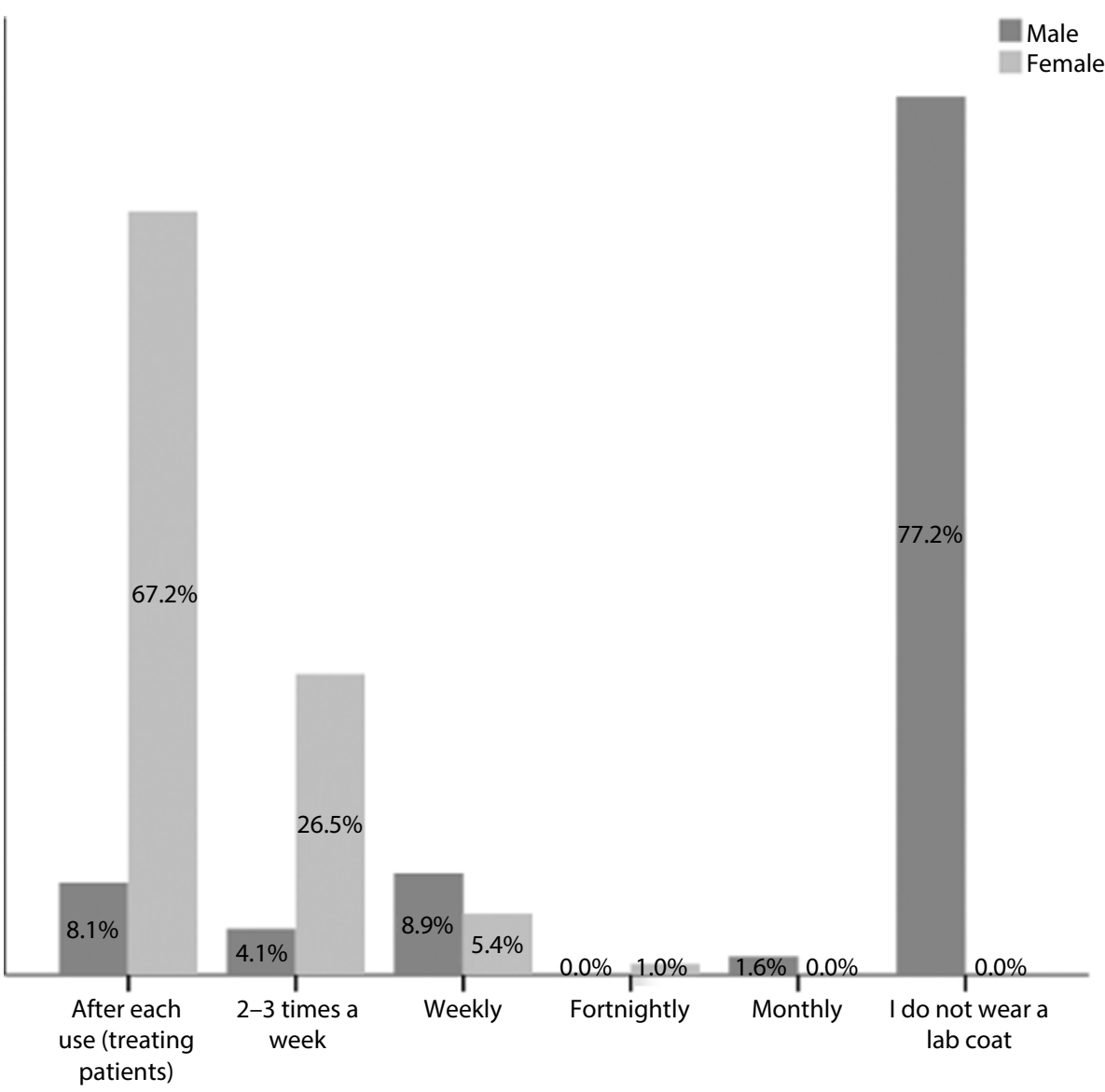

Figure 3 Frequency of washing lab coats.

Our current concern has been whether or not students abide by the locally established code of practice in terms of infection control in the clinics. Despite the fact that PPE is mandatory during clinical procedures, some students do not comply and are not reprimanded. If students also followed the guidelines for clinical attire and how to handle it in terms of washing and disinfecting mandatory accessories such as identification badges, it would somewhat appease the gravity of not wearing PPE. The rationale of installing various seemingly redundant policies is a risk assessment strategy that further reinforces a safety culture and is the strategy followed by our institute.

Our results concluded that uniform-related infection control practices differ significantly between genders. Almost all female students wear lab coats as part of their daily uniform, unlike the majority of males; however, $22.7 \%$ of male students reported washing their lab coats at different time intervals which suggests that more male students wear lab coats but not often enough to consider them as part of their daily uniform.

Male students mostly wear only scrubs, while female students wear either scrubs or everyday clothing under their lab coat. The difference in uniforms between genders is due to the different uniform code set by the school that takes into consideration the obligations of Islamic law followed by the country. ${ }^{15}$ According to the NHS, the cuffs at the wrist become heavily contaminated and are likely to come into contact with the patient, thus long-sleeved lab coats should not be worn while treating patients unless it is possible to roll or pull back the sleeves and keep them secured while treating patients and performing hand hygiene. ${ }^{16} \mathrm{~A}$ study by Munoz-Price et al ${ }^{17}$ supports the NHS recommendations as it concludes that there is an association between the contamination of providers' hands and contamination of white coats, yet no association was observed between providers' hands and scrubs. Generally, scrubs tend to have short sleeves and disposable gowns are worn over them. ${ }^{18}$ Since almost all female students wear long-sleeved lab coats, care must be taken to avoid cuff contamination. Some female students are reluctant to roll up their lab coat sleeves despite wearing gowns, and this needs to be addressed in a tactful manner. One possible solution is requiring female students to roll their sleeves up one third of their forearm and covering the exposed part with a disposable gown that is part of the PPE. This can be emphasized 


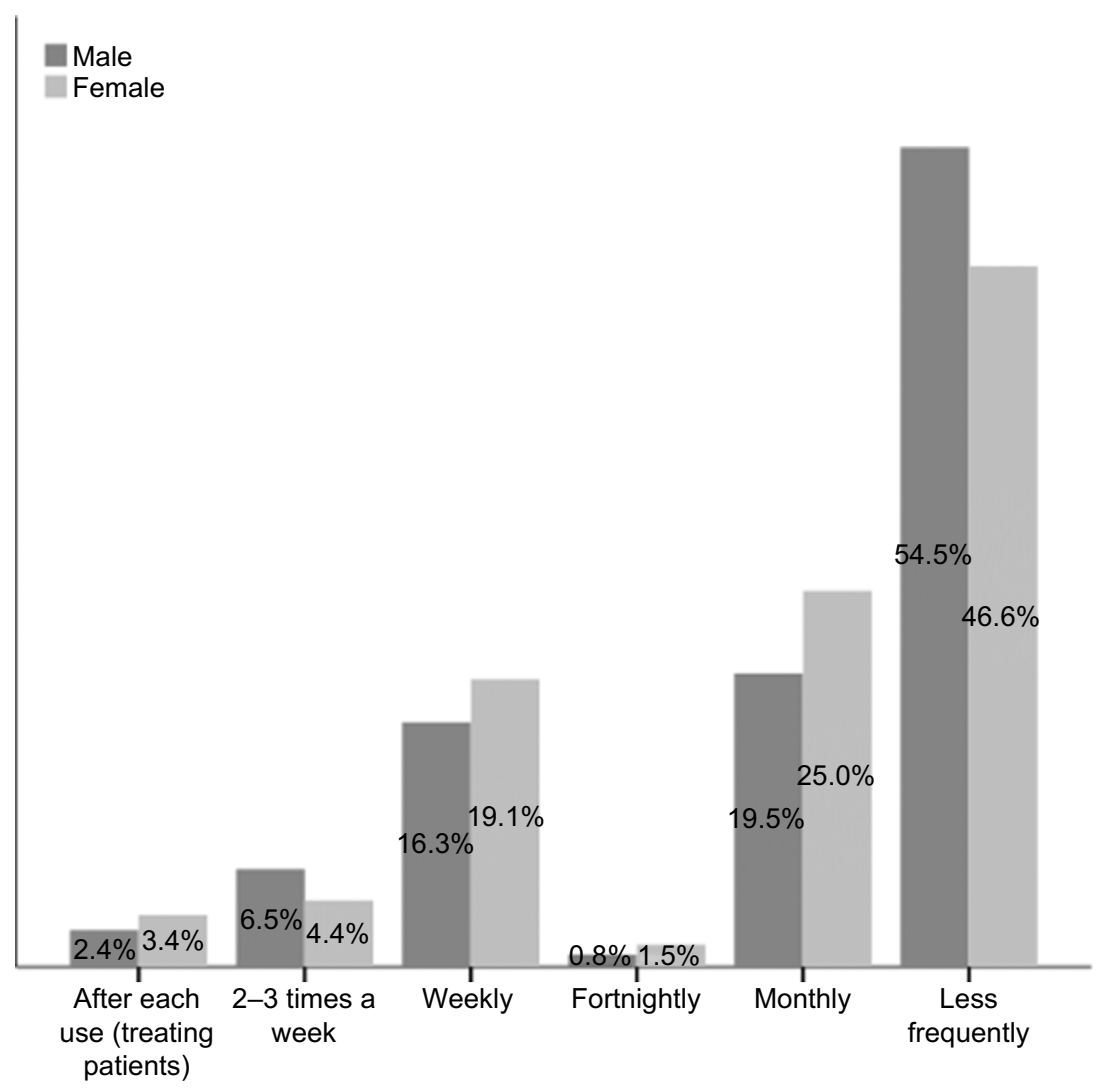

Figure 4 Frequency of washing footwear.

and taught during the orientation week at the beginning of the year. Furthermore, the consideration of hijab (Islamic head cover) needs to be addressed. The typical head cover in Saudi Arabia is in the form of a tarha which is similar to a long scarf (up to $2 \mathrm{~m}$ long) that is wrapped once or twice around the head. When wrapped once, it leaves the two ends hanging on both sides of the shoulders to the front and is therefore potentially in close proximity to the patient. Diligent wearing of PPE would take care of the potential hazard, but if a disposable gown is not worn, this easily becomes soiled. We have not included this in the current study, but a policy whereby female students are required to change their hijab in-between patients or at least during clinical procedures, may be instituted by the Infection Control Committee of the dental school to ensure that all possibilities are addressed in terms of contaminated wear.

Uniforms are more frequently contaminated below the waist, especially when using hand pieces; thus, footwear should not be omitted from the uniform. ${ }^{11,13}$ Our results revealed that $107(50.2 \%)$ female students and $49(38 \%)$ male students have footwear specifically for the dental clinic. As for the frequency of uniform washing, according to the school's infection control manual, the uniform should be changed daily or immediately if visibly soiled or contaminated, as it represents a source of contamination. ${ }^{19,20}$
However, many students do not follow the school's instructions. Only 61 (47.2\%) male students and 138 (64.7\%) female students wash their scrubs and everyday clothing worn in the clinics after each use, and almost half of the respondents (both genders) wash their footwear less frequently than monthly.

Some studies have reported that clinicians perceived lab coats differently to scrubs, thus lab coats are washed less frequently compared to scrubs. ${ }^{21}$ The same cannot be said for our female respondents since their uniforms mainly consisted of lab coats, and the fact that they wash their lab coats more frequently than their scrubs/everyday clothing worn in the clinics. As for the male students, their perception toward lab coats and scrubs cannot be analyzed because 29 (22.7\%) reported wearing lab coats but not often enough for them to be considered as part of their daily uniform and only $6(4.9 \%)$ reported wearing lab coats as part of their daily uniform. This cultural variation in the definition of a "uniform" must be taken into account and may necessitate a different protocol for male and female students.

Clinical uniform disinfection methods in our survey included parameters such as washing uniforms separately from other household clothes, using bleach, and disinfecting the name badge/hospital card. For the first two parameters, we added "I do not know" as a choice since not all students do their own laundry. A limitation of the disinfection methods is that we did not ask about the water temperature during 
the washing cycle, even though a high temperature causes microbial reduction by facilitating the detergent's effect and by thermal disinfection. ${ }^{13}$ However, it should be noted that overloading the washing machine will reduce the washing efficacy, which in turn might cause cross-contamination. ${ }^{16}$

Although the NHS recommends that only heavily soiled uniforms should be washed separately and crosscontamination when clinical uniforms are washed with other household clothes is not based on evidence, there is still a potential risk of cross-contamination to other household members. Microorganisms and pathogens may infiltrate clinical uniforms that may be in contact with other normal clothes. This could potentially create a breach whereby clinical contaminants reach other members of a household. ${ }^{22}$

Almost one-fifth of the respondents, at the time of completing the questionnaire, did not know if their uniforms are washed separately or not, and only $36.7 \%$ of the respondents use bleach, while $29.36 \%$ did not know if bleach is used even though the school's infection control manual instructs students to use bleach (hydrogen peroxide rather than sodium hypochlorite, which is more gentle on fabric and not damaging to colors) that has a disinfectant activity. ${ }^{13,19}$ As for disinfecting the name badge/hospital card, 144 (42.2\%) respondents do not disinfect their name badge/hospital card and believe that it is not important as long as the badge/ hospital card is covered while treating patients.

The very small percentage of students who reported that they do not always wear disposable gowns warrants attention as the rules in the institute should be absolute in this matter, as it is known to significantly reduce microbial contamination. ${ }^{13,19}$ In turn, this makes it even more important that uniforms are also treated in a manner that sees them as being possibly contaminated.

According to Qureshi et al, the clinical uniform should be removed before leaving the workplace, even though there is no evidence of an infection risk from traveling and socializing while wearing the clinical uniform as long as it is not visibly soiled or contaminated. ${ }^{11,16}$ However, most of our students wear their uniforms at home and take it off once at home or even later in the day. This is seen also in a similar study by Canadian dental hygienists who reported that most of their students $(61 \%)$ wash their uniforms weekly, while our results revealed that most students wash their uniforms (scrubs and everyday clothing used in the clinics) after each use (58.1\%) and only some weekly (10.1\%), and as for lab coats, $63.3 \%$ of those who wear lab coats reported that they wash their lab coats after each use. ${ }^{23}$

The phenomenon of "socializing" while wearing clinical uniform is a global occurrence and is often perceived as unhygienic. ${ }^{24} \mathrm{~A}$ higher than expected percentage of students (73.6\% male students and $56.1 \%$ female students) admitted that they socialize (e.g., go out for lunch) in clinical uniform after treating patients (Table 1) ${ }^{16}$ Again, with particular reference to the current new threats of contagious diseases, this habit should be discouraged as much as possible.

The fact that this study represents data in the form of selfreport puts a great limitation to inferring actual facts from our results. However, due to the sensitive nature of the matter, a more cautionary approach is undoubtedly a safer approach.

\section{Conclusion}

Infected clothes are recognized as an infection risk even though there is no conclusive evidence that clothes have a direct role in spreading infection; however, if crosscontamination through clothing is possible, it could be easily minimized with different infection control precautions such as uniform washing after each use with the hottest temperature suitable for the fabric, along with the use of detergent or bleach when needed. Heavily soiled uniforms should be changed as soon as possible and washed separately from other household clothes. ${ }^{11,13,16,19,21}$

Our work highlights the uniform-related behaviors of students irrespective of their compliance with mandatory infection control guidelines of wearing PPE (in this instance, disposable gowns). As such, we also probed the Islamic attire guidelines in our ultraconservative institute. Understanding practices and compliance can help policy makers in the faculty in providing measures that respect all aspects of the culture. Information on preventing cross-contamination through uniform must be included in the school's periodical infection control training alongside other aspects of infection control practice. Students' infection control practices should become second nature and habitual with particular attention to wearing possibly contaminated uniforms in public places, which may place the community in danger. Continuous monitoring, reprimanding, and disciplinary actions in case of breach must be emphasized throughout the undergraduate clinical years to ensure these practices are upheld once the students graduate and enter the workforce.

\section{Limitations}

Unasked questions with regards to the uniform, such as wearing long-sleeved shirts under the scrubs, the type of lab coat (short-sleeved or long-sleeved) worn by male students who do wear lab coats, and whether female students wear specific head cover (hijab) in the clinical setting, are considered limitations and should be included in future uniform-related surveys. 


\section{Acknowledgments}

The authors express their gratitude to the students who agreed to participate in this work by providing their honest answers and time amidst their busy schedules. They would also like to thank the Institute's higher administration for providing them with access to distribute their questionnaire.

\section{Disclosure}

The authors report no conflicts of interest in this work.

\section{References}

1. Agostinho AM, Miyoshi PR, Gnoatto N, Paranhos H de FO, Figueiredo LC de, Salvador SL. Cross-contamination in the dental laboratory through the polishing procedure of complete dentures. Braz Dent J. 2004;15(2):138-143.

2. Yüzbasioglu E, Saraç D, Canbaz S, Saraç YS, Cengiz S. A survey of cross-infection control procedures: knowledge and attitudes of Turkish dentists. J Appl Oral Sci. 2009;17(6):565-569.

3. College of Dental Surgeons of British Columbia [homepage on the Internet]. Infection Prevention and Control Guidelines. College of Dental Surgeons of British Columbia; 2012. Available from: https:// www.cdsbc.org/practice-resources/professional-practice/standardsand-guidelines/infection-prevention-and-control-guidelines. Accessed February 26, 2017.

4. Harrel SK, Molinari J. Aerosols and splatter in dentistry: a brief review of the literature and infection control implications. J Am Dent Assoc. 2004;135(4):429-437.

5. Acharya S, Priya H, Purohit B, Bhat M. Aerosol contamination in a rural university dental clinic in south India. Int J Infect Control. 2010;6: $1-7$.

6. Bârlean L, Iancu LS, Minea ML, Dãnilã I, Baciu D. Airborne Microbial Contamination in Dental Practices in Iasi, Romania. OHDMBSC. 2010;9(1):16-20.

7. Fennelly KP, Jones-López EC, Ayakaka I, et al. Variability of Infectious Aerosols Produced during Coughing by Patients with Pulmonary Tuberculosis. Am J Respir Crit Care Med. 2012;186(5):450-457.

8. Veena HR, Mahantesha S, Joseph PA, Patil SR, Patil SH. Dissemination of aerosol and splatter during ultrasonic scaling: a pilot study. J Infect Public Health. 2015;8(3):260-265.

9. Bentley CD, Burkhart NW, Crawford JJ. Evaluating spatter and aerosol contamination during dental procedures. J Am Dent Assoc. 1994; 125(5):579-584.

10. Bercy P, Glorieux T. Diffusion microbienne par aérosol pendant les ultrasons; étude descriptive. [Microbial diffusion by aerosol during ultrasonic scaling: descriptive study]. Rev Belge Med Dent (1984). 1994; 49(3):35-41. French.

11. Qureshi UM, Siddiqui S, Macfarlane TV. Cross infection: How frequently do dentists change into a clean set of clinical clothing? Health Education Journal. 2005;64(2):101-109.
12. Centers for Disease Control and Prevention [homepage on the Internet]. Infection Prevention \& Control in Dental Settings. CDC; 2013. Available from: www.cdc.gov/oralhealth/infectioncontrol. Accessed February 26, 2017.

13. Wilson JA, Loveday HP, Hoffman PN, Pratt RJ. Uniform: an evidence review of the microbiological significance of uniforms and uniform policy in the prevention and control of healthcare-associated infections. Report to the Department of Health (England). J Hosp Infect. 2007;66(4):301-307.

14. Fijan S, Šostar Turk S. Hospital textiles, are they a possible vehicle for healthcare-associated infections? Int J Environ Res Public Health. 2012;9(9):3330-3343.

15. dentistry.kau.edu.sa [homepage on the Internet]. Islamic Ethics and Code of Professional Conduct. [Internet]. Jeddah: KAUFD; 2016. Available from: http://dentistry.kau.edu.sa/content.aspx?Site_ $\mathrm{ID}=165 \& \operatorname{lng}=\mathrm{AR} \& \mathrm{cid}=43775 \& \mathrm{URL}=$ www.kau.edu.sa. Accessed February 26, 2017.

16. DH/CNO Directorate/Patient Environment Team. Uniforms and workwear: Guidance on uniform and workwear policies for NHS employers. 2010;16. Available from: https://www.google.co.nz/ url? $\mathrm{sa}=\mathrm{t} \& \mathrm{rct}=\mathrm{j} \& \mathrm{q}=\& \mathrm{esrc}=\mathrm{s} \&$ source $=$ web $\& \mathrm{~cd}=1 \& \mathrm{cad}=\mathrm{rja} \&$ uact $=8$ \&ved=0ahUKEwinjeKM-ffSAhWLXbwKHRtTAg8QFggYMAA\& url=http $\% 3 \mathrm{~A} \% 2 \mathrm{~F} \% 2 \mathrm{Fwww}$.ncuh.nhs.uk\%2Fabout-us\%2Ffreedom-

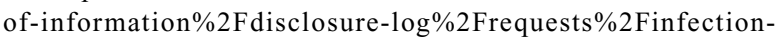
control\%2F000771-09.pdf\&usg=AFQjCNHMRICS7ial2cqPfR4osM 9XS0Z2fg\&sig2=vZiovDaW6CkF8BEGefxQFQ\&bvm=bv.1507297 34,d.dGc. Accessed June 1, 2016.

17. Munoz-Price LS, Arheart KL, Mills JP, et al. Associations between bacterial contamination of health care workers' hands and contamination of white coats and scrubs. Am J Infect Control. 2012;40(9): e245-248.

18. Laufman H, Belkin NL, Meyer KK. A critical review of a century's progress in surgical apparel: how far have we come? J Am Coll Surg. 2000;191(5):554-568.

19. dentistry.kau.edu.sa [homepage on the Internet]. Infection Control Manual. The college committee of fighting infection. Jeddah: KAUFD; 2015. Available from: http://dentistry.kau.edu.sa/content.aspx?Site $\mathrm{ID}=165 \& \operatorname{lng}=\mathrm{AR} \& \mathrm{cid}=43775 \& \mathrm{URL}=$ www.kau.edu.sa. Accessed February 26, 2017.

20. Harfst SA. Personal barrier protection. Dent Clin North Am. 1991; 35(2):357-366.

21. Munoz-Price LS, Arheart KL, Lubarsky DA, Birnbach DJ. Differential laundering practices of white coats and scrubs among health care professionals. Am J Infect Control. 2013;41(6):565-567.

22. Mitchell A, Spencer M, Edmiston C Jr. Role of healthcare apparel and other healthcare textiles in the transmission of pathogens: a review of the literature. $J$ Hosp Infect. 2015;90(4):285-292.

23. Leivers M, Tangri E, Noren KN, Hirji SK, Hernandez G, Kaminska BD, Do HL. Uniform contamination in the dental environment. Canadian J Dent Hygiene. 2012;(46):1:50.

24. Loveday HP, Wilson JA, Hoffman PN, Pratt RJ. Public perception and the social and microbiological significance of uniforms in the prevention and control of healthcare-associated infections: an evidence review. J Infect Prevent. 2007;8(4):10-21.
Infection and Drug Resistance

Publish your work in this journal

Infection and Drug Resistance is an international, peer-reviewed openaccess journal that focuses on the optimal treatment of infection (bacterial, fungal and viral) and the development and institution of preventive strategies to minimize the development and spread of resistance. The journal is specifically concerned with the epidemiology of antibiotic

\section{Dovepress}

resistance and the mechanisms of resistance development and diffusion in both hospitals and the community. The manuscript management system is completely online and includes a very quick and fair peerreview system, which is all easy to use. Visit http://www.dovepress.com/ testimonials.php to read real quotes from published authors. 